\title{
Entrevista com Lionel Elvin
}

\author{
Maria Lúcia G. Pallares-Burke e Peter Burke \\ tradução de Sandra Vasconcelos
}

Lionel Elvin (nascido em 1905) é um belo exemplo de certo tipo de inglês, um intelectual que se tornou administrador sem perder seu entusiasmo pela vida da mente, e um rapaz da classe trabalhadora cuja carreira na O rganização das $\mathrm{N}$ ações $\mathrm{U}$ nidas para Educação, C iência e C ultura (U nesco) e na universidade nunca 0 distanciou dos valores radicais de sua juventude. D epois de dar aulas de literatura inglesa no Trinity $\mathrm{H}$ all, em $\mathrm{C}$ ambridge, e trabal har como funcionário público temporário durante a Segunda Guerra M undial, Elvin tornou-se diretor do R uskin College, de 0 xford, em 1945, uma instituição fundada com a finalidade de fornecer aos futuros líderes do movimento sindical a oportunidade de uma educação universitária.A os cinco anosem 0 xford seguiram-se seis anos em Paris, trabal hando para a U nesco como administrador educacional, oportunidade que permitiu a Elvin ver o sistema britânico não apenas de uma perspectiva européia mas também global. É pena que ele tenha chegado à U nesco tarde demais para conhecer o nosso grande educador A nísio Teixeira (1900-1971), conselheiro de ensino superior nesse órgão em 1946 e 1947, já que esses dois homens têm muito em comum e teriam tido muito a dizer um ao outro.

A experiência de Elvin na U nesco fez dele um candidato natural para o cargo de professor titular em Educação Tropical - em outras palavras, educação no I mpério Britânico - na U niversidade de Londres. Logo ele se tornou diretor do Instituto de Educação, cargo que manteve de 1958 até sua aposentadoria em 1970. 
Autodefinindo-se como um "socialista democrático" e um velho apoiador do Partido Trabalhista britânico (do qual foi candidato ao Parlamento, certa feita), Lionel Elvin foi conselheiro do governo no tocante à política educacional e membro de muitas comissões, notadamente o R obbins $\mathrm{C}$ ommittee on Higher Education (1963), que propôs importantes reformas no sistema universitário britânico. Sua abordagem da educação sempre foi caracterizada pela preocupação com a justiça social, com métodos democráticos, e pelo bom senso (um de seus livros tem o título de The place of common sense in educational thought, 1977). Ele procurou, ao longo de sua carreira pública, adaptar as escolas e as universidades ao mundo em mudança, ao mesmo tempo em que preservou o que considerava ser os melhores elementos da tradição, do estudo de Platão ao sistema de colleges de C ambridge.

H omem modesto (que nos afirmou estar surpreso, "por que alguém no B rasil quereria saber a meu respeito?"), extremamente simpático e ainda muito alerta, lúcido e independente, apesar de sua idade, Lionel Elvin nos recebeu na sala de estar de sua ensolarada casa moderna nos arredores de $C$ ambridge. U m pouco desconfortável com a situação e um tanto desconfiado da tecnologia moderna, Lionel Elvin, de modo educado mas firme, nos pediu para desligar o gravador enquanto falava com vivacidade e perspicácia - embora menos sobre certos tópicos, como, por exemplo, seu ex-aluno R aymond W illiams, do que desejaríamos- a respeito de suas opiniões e experiências na política e na educação.

Bastante autocrítico, no tradicional estilo inglês, começou a entrevista dizendo: "N ão sei por que vocês estão me entrevistando. Estou fora de moda agora, sou só um banco de dados da nostalgia!"

0 senhor poderia nos dizer algo sobre seus antecedentes familiares, suas primeiras experiêndas escolares e por que escolheu ir para $\mathrm{C}$ ambridge para estudar $\mathrm{H}$ istória? I sso não era pouco comum, na década de 1920, para alguém de sua origem?

1. Em 1905, East End era uma área pobre de Londres (nota de M . L. Pallares-Burke e P. Burke).

2. Lanceiros de Bengala eraum regimento da $\mathrm{Ca}$ valaria das Forças A rma das B ritânicas na Índia.
M inha família veio do East End de Londres. T ive ótimos pais e dois bons irmãos. M inha mãe era filha de um pastor. Ela lia Dickens eT hackeray para nós. M eu pai viveu na Índia até os sete anos, pois meu avô era parte dos $L$ anceiros de $B$ engala ${ }^{2}$. M eu pai trabalhou numa firma de mineração até decidir dedicar-se ao sindicalismo. Foi secretário-fundador do $\mathrm{N}$ ational $\mathrm{U}$ nion of C lerks (profissão àquela época dominada pelos homens, tendo só bem mais tarde atraído as mulheres) e depois presidente do Trade U nion Congress.

Freqüentei a Southend $\mathrm{H}$ igh School. A escola não se encaixava nas categorias normais. Pagava-se uma pequena taxa, três guinéus por semestre - 0 que não era pouco dinheiro para minha família -, mas as crianças tinham 
todos os tipos de talentos trabalhados. $\mathrm{N}$ os meus primeiros anos ali, coincidentes com o fim da Primeira Guerra M undial, os professores eram quase todos substitutos. Tenho uma grande dívida para com meu professor de $\mathrm{H}$ is tória, que era um estudioso. Ele era secretário da British Archaelogical Association e levava osmeninos para ver as igrejas e outros lugares de interes se. Foi ele quem me ajudou a conseguir a bolsa para $\mathrm{C}$ ambridge. Sempre quis estudar Literatura Inglesa (talvez efeito de tanto escutar DickenseT hackeray), mas não havia bolsas nessa disci plina. A ssim, cursei $\mathrm{H}$ istória durante dois anos e depois mudei para Literatura Inglesa. $N$ ão por causa de Frank Leavis, pois era cedo demais para isso. A prendi com Leavis, mas nunca fui seu seguidor devoto. Q uanto a seus conflitos com os colegas, havia dificuldades de ambos os lados, como sempre3. Leavis era paranóico.

$\mathrm{N}$ ão fui infeliz em Cambridge, mas ali descobri a consciência de classe, não entre os professores mas entre os alunos de graduação (houve grandes mudanças desde então). Eu era bom em esportes (ganhei uma medalha no atletismo), de modo que me saí bem, ou quase bem. M as não tinha amigos nas escolas independentes e jamais teria entrado em seus aposentos sem um convite formal. M eu amigo Pumfrey, que foi para uma escola independente, achava, quando foi para a universidade, que os estudantes da escola pública eram "merdas" . N ão, não achei C ambridge "elitista", no sentido de preconceituosa, por parte dos professores universitários. Essa é uma noção moderna. Fala-se muita bobagem sobre isso agora. 0 sprofessores tinham a mente aberta, desejavam mesmo ampliar a base social do college.

Sua carreira parece ter sido extremamente variada. Poderia nos contar qual foi 0 interesse que os diferentes cargos que ocupou tiveram para 0 senhor? E $\mathrm{m}$ seu primeiro emprego - ensinar Literatura Inglesa no Trinity $\mathrm{H}$ all, em C ambridge, 0 senhor teve um aluno que iria se tornar um dos mais famosos etalentosos críticos literários, $R$ aymond W illiams. C omo ele era como aluno?

Depois de C ambridge, fui professor durante dois anos em Yale. Escrevi para o SeniorTutor deTrinity $\mathrm{H}$ all pedindo conselhos sobre o que deveria fazer em seguida e ele me respondeu dizendo, "N ão faça nada.Vamos elegê-lo fellow na terça-feira". Essa foi decerto uma das melhores cartas que recebi na minha vida. Assim, fui dar aulas de Literatura Inglesa no Trinity $\mathrm{H}$ all. U m de meus melhores alunos foi $\mathrm{R}$ obin $\mathrm{M}$ augham, sobrinho do romancista ${ }^{4}$.Também dei aulas para $\mathrm{R}$ aymond $\mathrm{W}$ illiams no primeiro ano dele em $\mathrm{C}$ ambridge, quando ele estava sofrendo de choque cultural e achava difícil decidir se seguia Leavis ou M arx. Lembro-me de dizer-Ihe que ele tinha de escolher e não podia ficar com ambos. Isso durou até a guerra (Segunda G uerra M undial), quando
3. Leavis era um crítico literário de esquerda, que foi modelo para muitos estudantesnaépoca. Criou muitas inimizades pelos ataques francose agressivosno que escrevia[N ota deJoséde Souza M artins].

4. $R$ obin M augham era sobrinho de W. Somerseth $M$ augham e filho do Lord Chancellor. Como o tio paterno, tornou-se escritor e novelista. U m de seuslivros, T heservant, foi adaptado para o cinema e baseiz-se num episódio com ele ocorrido em Trinity $\mathrm{H}$ all. $\mathrm{R}$ obin $M$ augham estava dividido entre seguir o pai na política ou o tio na literatura. Foi Lionel Elvin quem o influenciou para a literatura. A té hojeTrinity $\mathrm{H}$ all mantém um forte interesse na literatura, celebrada numa conferência anual dedicada à memória de Sir Lesie Stephen, que foi pai deV irginia Woolf e fellow do college (nota de José de Souza M artins). 
me tornei funcionário temporário do M inistério do Ar e depois do M inistério da Informação.

D epois da guerra, tive de decidir se deixava ou não o Trinity $\mathrm{H}$ all para tornar-me diretor do R uskin College em 0 xford, o college para os sindicalistas. Fiquei lácinco anos. Daí passei seisanosnaFrança trabalhando paraaU nes co. C omo cheguei lá? 0 que importa não é o que se faz, mas quem se conhece. U m amigo meu, John M aud, era presidente do Comitê Executivo da U nesco. Desse modo, ofereceram-me o emprego. Foi um desafio, abrir uma janela para o mundo, embora fosse uma vida frenética, e a U nesco, em sua organização interna, fosse muitas vezes um pouco louca.

D epois fui convidado para ser professor de Educação T ropical no Instituto de Educação da U niversidade de Londres, talvez porque a minha experiência na U nesco tenha me tornado interessado em educação no que agora se chama deTerceiro M undo. "Tropical" era um eufemismo para educação nas colônias britânicas. Levei um minuto - e minha mulher 30 segundos - para aceitar o convite (em 1956). Pouco depois, o diretor do Instituto de Educação morreu repentinamente. $\mathrm{N}$ ão me candidatei ao emprego, jáque não tinha experiência nesse cargo, mas fui convidado para ser diretor e aceitei.

0 senhor se descreveria como um homem de esquerda e como um ativista que se opôs fortemente ao Império B ritânico? 0 M arxismo al guma vez 0 atraiu? Q uais são suas opiniões sobre $\mathrm{O}$ N ovo Trabalhismo de B lair?

Sim, fui ativista político. A poiei os trabalhadores durante a Greve Geral (em 1926), diferentemente da maioria dos alunos de $C$ ambridge que ajudaram a boicotá-la. H avia cartazes no college conclamando os estudantes a boicotar a greve. Eu quis colocar um cartaz conclamando os estudantes a apoiar a greve, mas meu professor, um pseudoliberal, não permitiu. "Trata-se de uma questão da sua classe contra a minha", foi sua resposta. Eu deveria ter ido ao Senior Tutor; ele teria permitido. Aí, fui candidato ao Parlamento por um distrito eleitoral muito atrasado, a U niversidade de C ambridge, que, até 1945 , tinha o direito de mandar dois membros para o Parlamento.

Vocês poderiam me chamar de um socialista democrático. 0 marxismo me atraiu até certo ponto. $\mathrm{N}$ ão se pode ignorá-lo. $\mathrm{M}$ as não quero ser vítima

5. R. H. Tawney era socialista e professor de $\mathrm{H}$ is tóriaE conômica na London School of Economics (nota de M. L. PallaresBurke e P. Burke). de uma ideologia dogmática. Concordo com $\mathrm{H}$ arold Laski, que diz que as raízes do socialismo britânico são éticas, não marxistas. Parecia injusto que tão pouco do excedente econômico fosse para os trabal hadores. R . H .Tawney ${ }^{5}$ foi um herói para mim. Conheci-o bem, quando ele era presidente e eu secretário do Distrito Leste daW EA (Workers' Educational A ssociation). Ele foi um grande homem e me influenciou mais do que qualquer outro. D ei a 
mesma resposta que ele, quando Edward Boyle ofereceu-me o título de Sir, na década de $1960^{6}$. Q uanto a Blair, ele é um desastre. Enganou o Partido Trabalhista, transformando- o num partido capitalista com uma face humana.

Q uanto ao Império Britânico, tenho de modular minha resposta. N ão tínhamos qualquer direito de governar os indianos. Fiquei contente com a independência da Índia, que aconteceu no governo de Attlee. M as a última fase, os últimos dez anos mais ou menos, foi louvável. A maior parte dos funcionários civis coloniais deu o melhor de si para preparar as colônias para a independência.

C erta feita, o sociólogo $D$ avid $R$ iesman comparou o processo de educação ao processo de descoloniz ação. D ada a sua experiência de ambos, o senhor concorda? C olocando a questão de forma mais ampla: suas atitudes políticas vinaulam-se a suas idéias sobre a educação?

Sim, penso que a política e a educação estão ligadas. N ão se pode ter uma sociedade socialista sem educação. A W EA desempenhou um papel importante ao oferecer algum tipo de educação superior às pessoas que depois se tornaram membros do Parlamento e líderes sindicais. $\mathrm{N}$ ão se tratava de doutrinação, mas de educação liberal. 0 sWebbs ${ }^{7}$, por exemplo, não queriam que a LSE [London School of Economics] fosse um órgão do Partido Trabalhista. Eles acreditavam que os fatos falavam por si, ou, como costumava dizer C. P. Scott, editor do M anchester G uardian, "osfatos são sagrados, a opinião é livre". Sempre houve um amplo espectro de opinião política na LSE, de Laski a H ayek. U ma vez, tentei persuadir Ludwig Erhardt, o chanceler alemão, de que a LSE não era um órgão do Partido Trabalhista, mas ele se recusou a acreditar em mim!

A Lei da Educação de 1944 representou um passo à frente. Significou educação secundária gratuita, embora fizesse concessões demasiadas às escolas confessionais. A credito nas comprehensive schools, com uma ressalva importante, a de que deveriam terminar aos 16 anos. Fui um dosprimeiros apoiadores da idéia da Sixth F orm. Ela ajuda os jovens adultos a tornarem- se adultos. Em todo caso, não havia qualquer possi bilidade de ter uma boa Sixth F orm em cada escola secundária moderna. N aturalmente, há uma imensa variação no interior do sistema de comprehensive schools. U ma das minhas tarefas como diretor do Instituto era premiar as melhores escolas, e em uma comprehensive school recitava-se em francês (era possível fechar os olhos e pensar que se estava na França), em alemão, latim e grego - um padrão alto, resultado de professores especialistas. Essa variedade torna injusto medir o progresso por meio de resultados de exame, já que uma comprehensive school pode estar localizada em uma

7. Beatrice e Sidney Webb, que, em 1895, fundaram a London School of Economics (nota de José de Souza M artins). 
área rica, outra em uma área pobre ou em uma em que a primeira língua não é 0 inglês.

H ouve grandes mudanças nos padrões acadêmicos. Há sessenta anos, a educação era melhor nas escolas públicas do que nas independentes, que ignoravam a ciência. M as isso mudou nos últimos trinta anos, e as escolas independentes têm mais recursos. Fui convidado para ser diretor de uma escola independente, gerida pela Society of Friends, na qual a proporção professor/aluno era de um para doze, um bom uso do dinheiro.

0 senhor ainda pensa que a educação britânica é, como escreveu em 1965, " grotescamente superespecializada" ? 0 senhor acredita que os dássicos são relevantes para a educação no mundo de hoje e que ainda é uma boa idéia ensinar Platão no séaulo XXI? E os ideais progressistas de Summerhill, deveriam ser imitados?

M elhorou um pouco. Costumava haver um contraste enorme com a F rança e com aA lemanha, com sete ou oito matérias no bac ou o A bitur comparado a três $A$ levels $D$ e modo que era possível conhecer um cientista francês que podia conversar sobre W illiam Blake; imagine encontrar um cientista inglês pronto para conversar sobreVerlaine! $\mathrm{N}$ aturalmente há um lugar para a especialização até certo ponto, especialmente na matemática e na música. M as um estudo de Peterson descobriu que os próprios estudantes queriam fazer quatro ou cinco matérias, menos do que na França ou na A lemanha, mas mais do que na Inglaterra. É assim que as coisas têm caminhado por aqui.

Sem dúvida, houve um declínio dos clássicos. Há menos tempo no currículo para o estudo do grego e do latim, e é importante usá-lo para ensinar mais como ler do que escrever poesia grega ou falar latim. D everia haver diferentes pontos de entrada nos clássicos. A gora os estudantes vão em grandes grupos para a $G$ récia; deveriam saber algo sobre o mundo antigo. Q uanto à tradução, pode-se obter muito com ela, mas não a poesia. Em $R$ uskin, quando era diretor, dei aulas de teoria política. Dizia a eles que passaríamos o primeiro semestre estudando a R epública de Platão em tradução. Seus semblantes mostravam uma expressão desapontada. Explicava a eles que há duas coisas que deveriam ter em mente ao mesmo tempo e que Platão os ajudaria a fazer isso. A primeira delas era de que a política é a mesma em toda parte porque os problemas são os mesmos. A segunda era de que a política é diferente em toda parte porque as circunstâncias são diferentes.

M inha mensagem para o próximo século seria: dêem cabo da divisão de classe entre a educação pública e a independente. A vida social inglesa é governada por essa divisão. N ão seria fácil colocar um fim nela; no entanto, muitos professores de escolas independentes Ihe dariam boa acolhida. 0 status de 
caridade das escolas independentes poderia ser condicionado a uma ampliação gradual de suas admissões. Eton poderia resistir, mas algumas escolas estariam dispostas a cooperar.

A. S. N eil, fundador de Summerhill, era um homem bom, particularmente no trato com alunos difíceis ou infelizes. M as era mais terapeuta do que professor. N unca teria mandado um menino bem ajustado para lá. Era uma escola antiintelectual. $\mathrm{N}$ eil era um velho ainda revoltado com a educação escocesa de sua juventude.

\section{Resumo}

Esta entrevista representa um esforço para registrar algumas idéias do quase centenário Leonel Elvin, educador que desempenhou um papel muito importante na educação britânica e mundial (por intermédio da U nesco) nos anos de 1950 e 1960. A conversa com Elvin versa sobre suas origens familiares, sua formação, suas idéias políticas e sobre suas idéias educacionais. Palavras-chave: Política; Educação; Educação britânica; U nesco; Socialismo democrático; Ativismo político.

\section{Abstract}

This interview represents an effort to record some thoughts of Leonel Elvin, an almostcentenarian educationalist who played a major part in British and world education (viaU nesco) in the 50's and 60's. It deals with Elvin's early life, with his politics and with his ideas about education.

Key words: Politics; Education; Bristish education; U nesco; D emocratic socialism; Political activism.
M aria Lúcia PallaresBurke é professora aposentada da Faculdade de Educação da U SP e pesquisadora associada do C entre of Latin American Studies, da U niversidade de $\mathrm{C}$ ambridge.

Peter Burke é professor de História Cultural da $\mathrm{U}$ niversidade de $\mathrm{C}$ ambridge e fellow do Emmanuel College. 